interest and use in other areas. One such area-beam plasma interactions-is dealt with in Chapter 12.

Particularly satisfying foatures of the book are its depth and the way in which problems are given alternative treatments together with critical discussions. These qualities are important in view of the fact that the book is written as a research monograph at a level appropriate to advanced graduate students. Knowledge of linear theory is assumed. The treatment is almost entirely theoretical, and one seldom finds experimental evidence in support of the theories developed. A consequence of dealing with non-linear equations is the difficulty of obtaining analytic solutions. There are therefore, as one would hope and expect, a large number of figures presenting computer results. The problem of gaining physical insight from such results is recognized, and is tackled with some success.

This book, which is well referenced and adequately indexed, is written with authority derived from wide research and teaching experience, and constitutes a valuable and readable contribution to the literature on microwave tubes.

I. B. Boxt

\section{Thermal Neutron Scattering}

Edited by P. A. Egelstaff. Pp. $x v+523$. (London: Academic Press, Inc. (London), Ltd.; New York: Academic Press, Inc., 1965.) $115 s$.

THE investigation of molecules, of liquids and of solids by thermal neutron scattering rests on the idea that the intensitios of scattered particles which have lost energy and momentum are a measure of the density and corre. sponding spatial and time Fourier components of scattering powor. The measurement of these intensities involves refined techniques of mechanical or diffractional velocity determination, and requires reactor sources, moderators, and scintillator detectors or proportional counters. This volume surveys the development of the subject since the great advances in technique during the fifties made it a productive field of study. Although there are fourteen different authors, the unity of presentation is unusually good and as a consequence the book serves as an introduction to the subject that will be of value to the non-specialist molecular or solid state physicist. For the specialist, the volume will also be valuable, as the field is not over-endowed with review literature.

J. B. HASTED

\section{Beginning Geology}

By H. H. Read and Janet Watson. Pp. 246. (London: Macmillan and Co., Ltd., and George Allen and Unwin, Ltd.; New York: St. Martin's Press, 1966.) 30s. net.

AxтночGH the layman can probably appreciate geology more easily than almost any other science, geologists (with a few notable exceptions) are notoriously bad at transmitting the essence of their subject to the uninitiated. Read and Watson's writings admirably fill this gap in communication. Unfortunately, their book is aimed primarily at schoolchildren, so that the style is sometimes reminiscent of a patronizing matey teacher. Otherwise, I have nothing but praise for this book. The scope of the book is the field of geology; this is comprehensively covered, while the treatment, though simple, is deep, and fairly complex concepts (often not dealt with adequately in supposedly more advanced text-books) are presented. The choice of examples-so important in any phenomenological science -is judicious, as is the choice of diagrams and photographs, while the layout both pleases and aids assimilation of the contents. Illustrations are drawn to a large extent from the British Isles, but the book is not nearly as chauvinistic as many others in this respect. Even if it were not so reasonably priced, this book would still be a worthwhile buy for those who are "beginning geology".

\section{OBITUARIES}

\section{Sir Denis Browne}

Sir Denis Browne, who died on January 9, cen be called the father of paediatric surgery.

In his native Australia he was educated at King's School, Paramatta, New South Wales, and at the University of Sydney, where he obtained his M.B. He served during the First World War with the Australian Army Medical Corps. Afterwards he came to England and obtained his F.R.C.S. Most of his working life was spent at the Hospital for Sick Children, Great Ormond Street, where he was houseman, registrar and consultant. During the Second World War he was the leader of a surgical team in a casualty clearing station in the basement of the hospital. Browne's surgical interests ranged from genito-urinary surgery to orthopaedics, for which he developed and modified instruments, appliances and operations. He developed many instruments, including a needleholder, dissectors, plastic shears and tonsil forceps, and appliances which reflect his interest in the treatment of congenital deformities. There are splints for the treatment of elub foot and harnesses for the correction of spinal deformities and congenital dislocation of the hip. $\mathrm{H}_{\theta}$ led the treatment of this last condition by means of closed reduction and manipulation. He perfected the technique for the manipulative treatment of talipes equinus-a form of club foot-and repaired hare lip and cleft palate. In other fields of child surgery his inventions included a transthoracic approach and incision to correct congenital heart deformities, and an operation for undescended testicle.

Among the awards which Browne received for his services to paediatrics was the Dawson Williams Prize, and he was an honorary member of the French Society of Urology. His other activities included his four terms as president of the British Association of Paediatric Surgeons and membership of the B.B.C. General Advisory Council. He was also an expert shot; he preferred to ride in taxis, and would nover own a car.

\section{Dr. William Meggers}

William Hrederick Meggers died of a heart attack on November 19, 1966, aged 78. In 1958 he had retired as chief of the spectroscopy section of the U.S. National Bureau of Standards, which he joined in 1914 as a laboratory assistant, with a B.A. from Ripon College, an M.A. from Wisconsin and a Ph.D. from Johns Hopkins University, all in physics.

His early work, carried out with C. G. Peters, produced measurements of the refractive index of air which were used for more than 25 years. Later he worked on the determination of atomic energy levels for the analysis of spectra, which he did very well and in very great detail. Meggers also utilized the neutrons from atomic reactors to transmute gold to a single isotope of mercury, which he used to produce his mercury 198 lamp. This lamp gives off a green spectral line so pure that its wavelength can be determined to one part in one billion. The wavelength of this light has served as a working standard of measurement in spectroscopy and metrology throughout the world. Meggers was also among the first to observe atomic spectra in the infra-red region.

Meggers was active on a number of committees concerned with spectroscopy, and in 1949-51 he was president of the Optical Society of America, which gave him its two highest awards. He also received medals from the Franklin Institute of Pennsylvania, the Department of Commerce and the University of Liège. After his retirement, Meggers remained as a guest worker at the National Bureau of Standards, and continued to contribute to research in atomic spectroscopy. 